\title{
Open-Circuit Fault Detection Technique for Fault-Tolerant Bridgeless Boost Rectifier
}

\author{
R K Abdul Razak', K S Muhammad', R Baharom', A M I Mamat ${ }^{2}$ \\ ${ }^{1}$ Faculty of Electrical Engineering, Universiti Teknologi MARA,Shah Alam, Malaysia \\ ${ }^{2}$ Faculty of Mechanical Engineering, Universiti Teknologi MARA, Shah Alam, Malaysia \\ *Corresponding author E-mail: khaliesahrazak@gmail.com
}

\begin{abstract}
Unexpected failure in one of the switches in a converter will lessen the performance of a system and may even prompt to a sys tem failure. Therefore, to reduce the failure rate and to prevent unscheduled shutdown, a real-time fault detection is necessary. In this paper, a new technique to identify the exact location of the faulty switch based on single-phase bridgeless boost converter is proposed. The faulty switch is detected by analyzing the boost inductor current, switching mode and cycle of the input power supply. The information of the faulty switch will be used to redirect the current to any available path. Therefore, an uninterruptable and reliable power supply could be developed. The analysis of the proposed fault detection scheme is done by using PSIM simulation software.
\end{abstract}

Keywords: Bridgeless Boost Rectifier, Fault Detection, Fault-Tolerant, PowerSim, Faulty Switches.

\section{Introduction}

Recently, power converter is amongst the devices which is in high demands in market trend. This is due to high quantities of hybrid and electric cars release in market which require redundant features in this era of technology. However, power semiconductor failure known to be one of the main factor to the converter destruction. Consequently, evolution of fault-tolerant systems has been presented in previous research [1-3]. Fault-tolerant control methods and open switch fault detection are popular in those interested topics in research.

With a specific end goal to change converter configuration and evade from subordinate harm in a fault-converter, a fault detection algorithm ought to be reasonable which is fast recognition, basic configuration and exact estimation [4]. Basically, the major occurrence of fault can be divided into two types, which are opencircuit fault (OCF) and short-circuit fault (SCF) [5]. SCF can occurs due to various conditions such as cable leakage, switching devices failure and auxiliary power supply breakdown. SCF may contributes to power system breakdown. Along these lines, equipment based protection, for example, fuses and circuit breakers can be used as protection to keep the fault occurrence from ending up more harmful. Nevertheless, OCF may not resorting to a damage of a system but rather it might cause an unusual process or execution corruption. The OCF might occurs due to lift of the bonding wire, driver failure or short-circuit fault-induced rupture $[5]$.

Few researchers mentioned the importance of redundancy approached in power converters due to converter failure that leads to the troublesome often requiring additional repairs, and crucial implementation of destructive converters can be harmful [6]. The redundancy approached mentioned as well-known fault-tolerant features for the power converters. Fault-tolerant features function is to ensure the continuity of power of a converter. Subsequently, the fault-tolerant studies development introduces analysis of fault detection and protection methods (FDPM) that requires literature studies on the existing methods and techniques.

There have been many FDPM proposed over recent years which have their own advantages and drawbacks. The most popular FDPM are applied to modular multilevel converter that have high number of switches. The FDPM method introduced to this converter topologies are capacitor voltage estimation which presents a new voltage balancing control technique with fault detection and fault tolerant capability based on capacitor voltage estimation instead of direct measurement. This method has high complexity of the circuit with fault tolerant capability added [7]. In [8], measured current behavior is compared to the expected current behavior to detect the fault occurrence and its location due to gate signals and the sign of arm current. This method is simple and fast detection of fault. Besides, model predictive control method checking the voltage errors between the measured arm voltages and the estimated ones in the former control cycle [9]. This method can only detect and isolate the single open-circuit fault and it fails when multiple open-circuit faults occur simultaneously. Based on analysis on these literature studies, the detection of FDPM approached on modular multilevel converters are average. Except for one method which is based on the deviation's magnitude and current flow direction. This method has fast speed detection magnitude which is less than $20 \mathrm{~ms}$.

The proposed topology in this research is single-phase bridgeless boost rectifier. The focus on fault detection and protection methods in this study are narrowed down to fault detection techniques that must be simple enough to be implemented, accurate, and fast. There are some methods that have been introduced in recent papers which applies on single-phase converters and have fast fault detection speed which are source-to-ground voltage measurement of the floating MOSFET, drain to source voltage monitoring and diode-voltage signature [10-11]. However, there is no fault detection technique that focused on bridgeless converter or more specifically bridgeless boost rectifier. In this way, with the inspiration of having simple circuit configuration, ability to reroute the current 
path to other healthy switches after fault occurrence at any instant, a new technique to detect the exact location of the faulty switch for fault-tolerant bridgeless boost rectifier (FTBBR) is proposed.

\section{Fault Tolerant Bridgeless Boost Rectifier}

In this section, the FTBBR circuit configuration is explained. FTBBR is able to continuously supplying power to the load even if two out of four switches are open-circuited. The FTBBR circuit is shown in Figure 1 and the detailed circuit operation can be found in [12]. When OCF is occurred, the current flow will be channeled to any possible path by turning on any possible switch The channeling of the current is called as current reroute path (CRP).

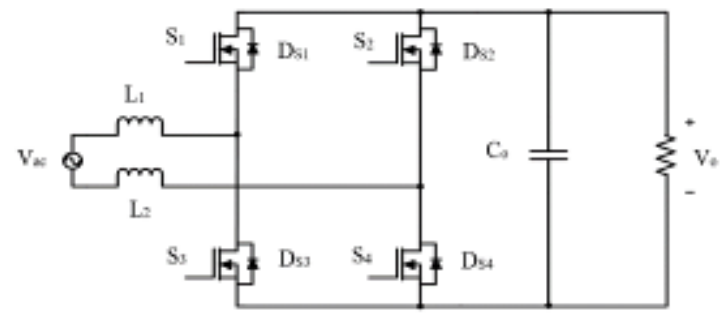

Fig. 1: The FTBBR circuit configuration [12]

The occurrence of fault can be characterized into four states as follows:

1. First state is when the upper and lower horizontal parallel pairs $\left(S_{1}\right.$ and $S_{2}$ or $S_{3}$ and $\left.S_{4}\right)$ or right and left vertical parallel pairs $\left(S_{1}\right.$ and $S_{3}$ or $S_{2}$ and $\left.S_{4}\right)$ are open-circuited. In this state, the FTBBR will have one CRP.

2. Second state is when the OCF take placed at one of the switches. In particular, the FTBBR has two alternative paths for CRP.

3. Third state is when the OCF take placed at the diagonal pairs $\left(S_{1}\right.$ and $S_{4}$ or $S_{2}$ and $\left.S_{3}\right)$. The FTBBR will be malfunctioned as there is no route for the current to flow. However, the converter will be operated as a full-wave uncontrolled rectifier i.e. by using the body diodes of the MOSFETs.

4. The fourth state is when only one switch is functioning. This state is forbidden because two switches are required to be turned-on in order to enable the current to flow.

The FTBBR is able to continuously operate as a full-wave uncontrolled rectifier over the diodes if the OCF occurs under the third and fourth state or even all switches are open circuited. Table 1 shows the summary of the fault possibility, $\mathrm{T}_{\mathrm{X}}$ and the state of the converter operation, where $\mathrm{X}$ is the possibility condition from $\mathrm{A}$ to P.

Table 1: Fault Possibility Table

\begin{tabular}{|c|c|c|c|c|c|}
\hline Fault possibility & $\mathbf{S}_{\mathbf{1}}$ & $\mathbf{S}_{\mathbf{2}}$ & $\mathbf{S}_{\mathbf{3}}$ & $\mathbf{S}_{\mathbf{4}}$ & Converter operation \\
\hline $\mathrm{T}_{\mathrm{A}}$ & 0 & 0 & 0 & 0 & Full-wave uncontrolled rectifier \\
\hline $\mathrm{T}_{\mathrm{B}}$ & 0 & 0 & 0 & 1 & Full-wave uncontrolled rectifier \\
\hline $\mathrm{T}_{\mathrm{C}}$ & 0 & 0 & 1 & 0 & Full-wave uncontrolled rectifier \\
\hline $\mathrm{T}_{\mathrm{D}}$ & 0 & 0 & 1 & 1 & CRP 1 \\
\hline $\mathrm{T}_{\mathrm{E}}$ & 0 & 1 & 0 & 0 & Full-wave uncontrolled rectifier \\
\hline $\mathrm{T}_{\mathrm{F}}$ & 0 & 1 & 0 & 1 & CRP 3 \\
\hline $\mathrm{T}_{\mathrm{G}}$ & 0 & 1 & 1 & 0 & Full-wave uncontrolled rectifier \\
\hline $\mathrm{T}_{\mathrm{H}}$ & 0 & 1 & 1 & 1 & CRP 1 and CRP 3 \\
\hline $\mathrm{T}_{\mathrm{I}}$ & 1 & 0 & 0 & 0 & Full-wave uncontrolled rectifier \\
\hline $\mathrm{T}_{\mathrm{J}}$ & 1 & 0 & 0 & 1 & Full-wave uncontrolled rectifier \\
\hline $\mathrm{T}_{\mathrm{K}}$ & 1 & 0 & 1 & 0 & CRP 4 \\
\hline $\mathrm{T}_{\mathrm{L}}$ & 1 & 0 & 1 & 1 & CRP 1 and CRP 4 \\
\hline $\mathrm{T}_{\mathrm{M}}$ & 1 & 1 & 0 & 0 & CRP 2 \\
\hline $\mathrm{T}_{\mathrm{N}}$ & 1 & 1 & 0 & 1 & CRP 2 and CRP 3 \\
\hline $\mathrm{T}_{\mathrm{O}}$ & 1 & 1 & 1 & 0 & CRP 2 and CRP 4 \\
\hline $\mathrm{T}_{\mathrm{P}}$ & 1 & 1 & 1 & 1 & All paths \\
\hline & & & &
\end{tabular}

\subsection{Generalized Steady State FTBBR Operation}

There are four current reroute paths (CRP) for FTBBR. Each CRP has four modes of operation which is same for all other paths. To additionally simplify the analysis, it is presumed that all components and devices are ideal.

1. CRP 1, OCF occurs at upper horizontal pair $\left(\mathrm{S}_{1}\right.$ And $\left.\mathrm{S}_{2}\right)$ At positive cycle, the inductor charges $\mathrm{L}_{1}$ and $\mathrm{L}_{2}$ and current flows through $\mathrm{S}_{3}$ and $\mathrm{D}_{4}$ as shown in Figure 1 (positive charging mode). Meanwhile, the output capacitor, $\mathrm{C}_{\mathrm{O}}$ is discharged through the load. The power from the input is transferred to the load through $D_{1}$ and $D_{4}$ when $S_{3}$ is turned off (positive discharging mode).

At negative cycle, the current charges inductor $\mathrm{L}_{1}$ and $\mathrm{L}_{2}$ and flows through $\mathrm{D}_{3}$ and when $\mathrm{S}_{4}$ is turned-on (negative charging mode). This mode is same as defined in positive charging mode. The input power is transferred to the load through $\mathrm{D}_{2}$ and $\mathrm{D}_{3}$ when $\mathrm{S}_{4}$ is turned-off (negative discharging mode). This mode is same to the positive discharging mode.

The current flows through similar path for all CRPs during positive and negative cycles at discharging mode,. Therefore, only the charging stage will be clarified from this point onward.

2. CRP 2, OCF occurs at lower horizontal pair $\left(\mathrm{S}_{3}\right.$ and $\left.\mathrm{S}_{4}\right)$ At positive cycle, both $\mathrm{L}_{1}$ and $\mathrm{L}_{2}$ will be charged through $\mathrm{D}_{1}$ when $S_{2}$ is turned-on. The output capacitor, $C_{O}$ is discharged through the load. At negative half cycle, $\mathrm{L}_{1}$ and $\mathrm{L}_{2}$ are charged when $S_{1}$ is turned-on where the current flows through $\mathrm{D}_{\mathrm{S} 2}$.

3. CRP 3, OCF occurs at left vertical pair $\left(S_{1}\right.$ and $\left.S_{3}\right)$

$\mathrm{L}_{1}$ and $\mathrm{L}_{2}$ are charged when current flows through $\mathrm{D}_{\mathrm{S} 1}$ and $\mathrm{S}_{2}$ during positive cycle charging stage while $\mathrm{L}_{1}$ and $\mathrm{L}_{2}$ are charged when current flows through $\mathrm{S}_{4}$ and $\mathrm{D}_{\mathrm{S} 3}$ during negative cycle charging stage.

4. CRP 4, OCF occurs at right vertical pair $\left(\mathrm{S}_{2}\right.$ and $\left.\mathrm{S}_{4}\right)$ The procedure of the occupied switches is same with CRP 3 but different for the exchange of the input power supply leg. At positive cycle charging stage, the current is flows through $\mathrm{S}_{3}$ and $\mathrm{D}_{\mathrm{S} 4}$ and charged $\mathrm{L}_{1}$ and $\mathrm{L}_{2}$ while during negative cycle charging stage the current will flow through $\mathrm{D}_{\mathrm{S} 2}$ and $\mathrm{S}_{1}$ and charged $\mathrm{L}_{1}$ and $\mathrm{L}_{2}$.

The switches configuration will be in the form of several combinations of more than one CRP if only one switch is open circuited.

\section{Open Circuit Fault Detection Technique}

In order to identify the location of the faulty switch is by observing output voltage, cycle of the input supply and inductor current. The output voltage is set to be at $400 \mathrm{~V}$. First the level of the output voltage will be check. If it is less than $400 \mathrm{~V}$, it shows that there is a problem with one of the switch. Then the cycle of the input supply need to be determined either it is during positive or negative cycle. After that the value of $\mathrm{I}_{\mathrm{L}}$ need to be measured to ensure that the inductor current is zero. Once the inductor current is measured, the location of the faulty switch could be determined. Figure 2(a-d) show the flowchart to detect the faulty switch for all CRPs. 


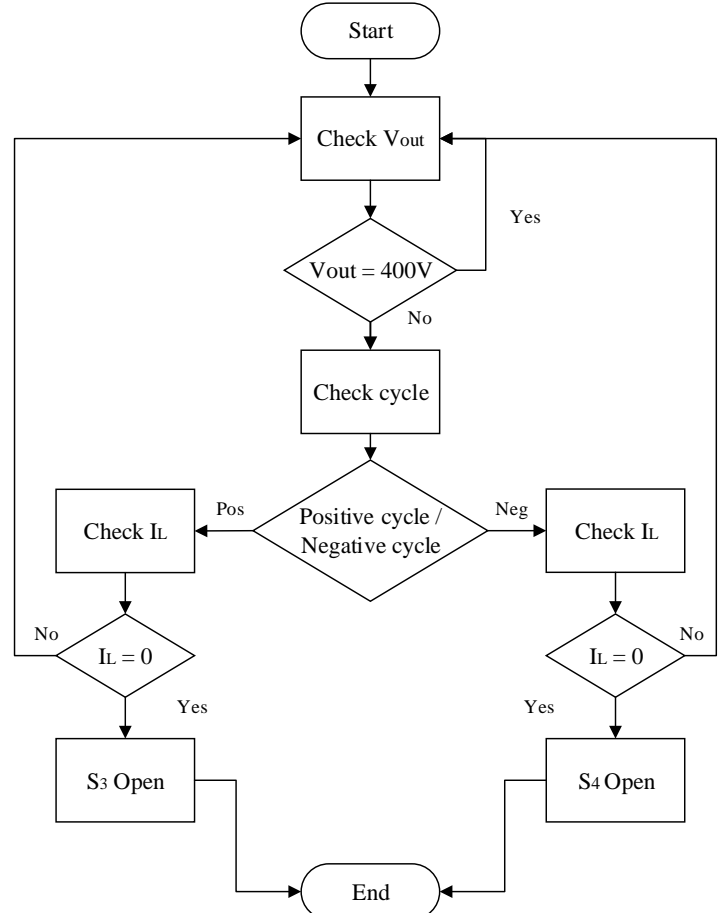

Fig. 2(a): Flowchart of CRP 1

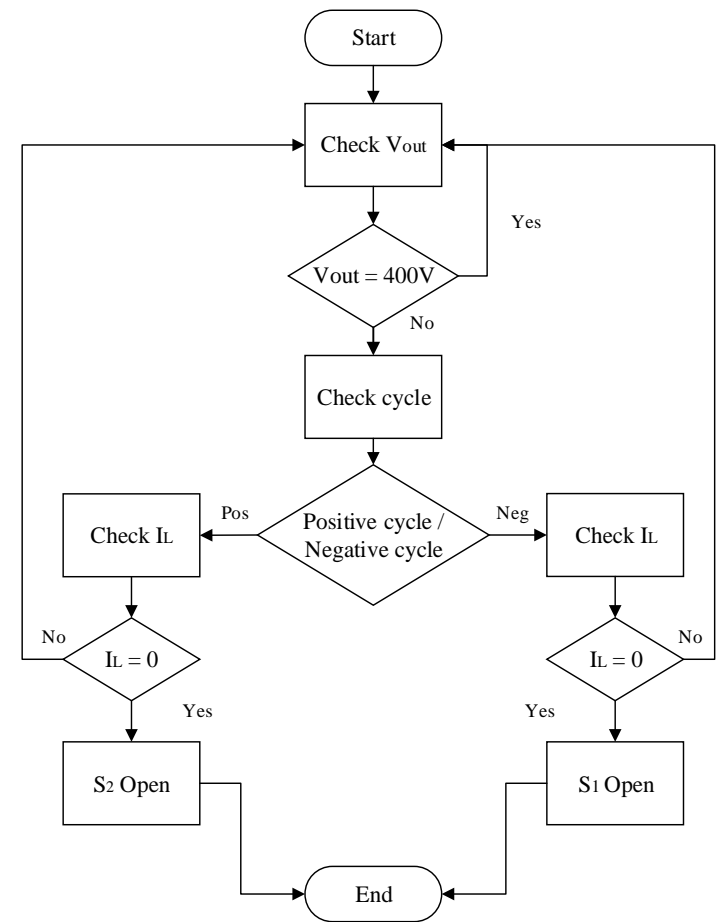

Fig. 2(b): Flowchart of CRP 2

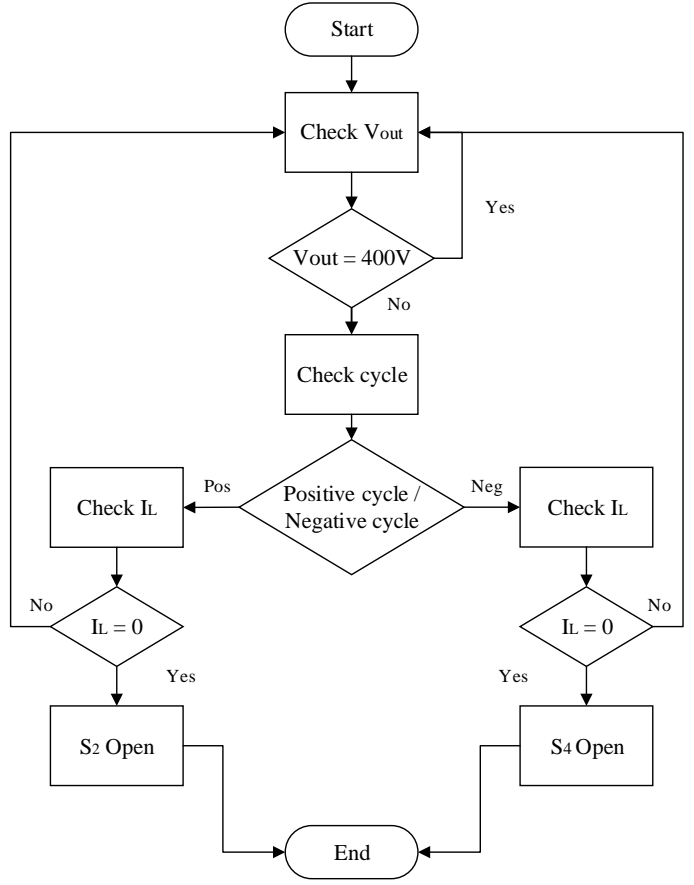

Fig. 2(c): Flowchart Of CRP 3

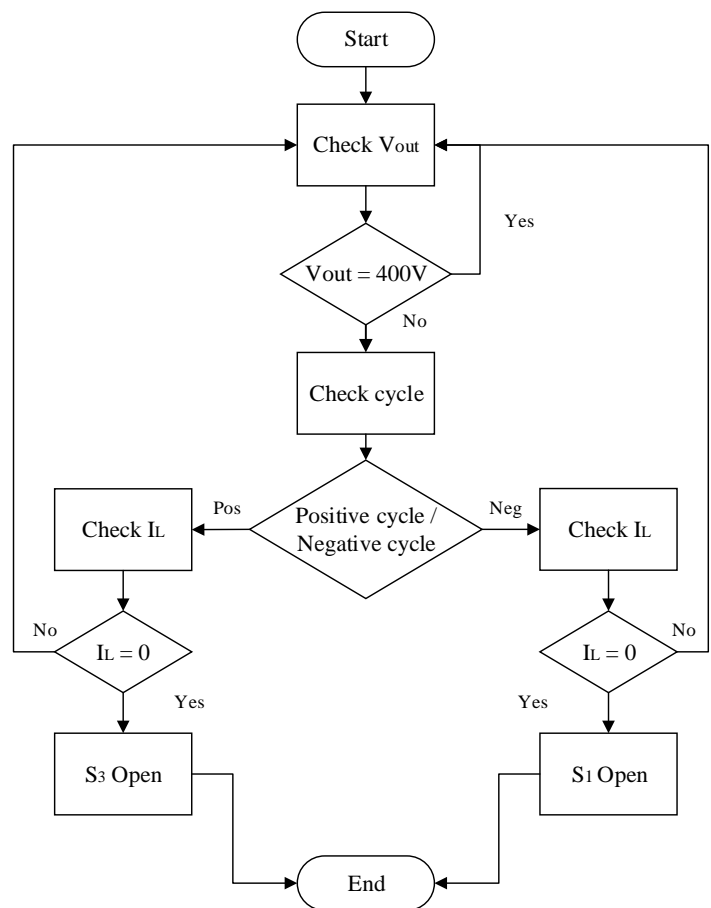

Fig. 2(d): Flowchart Of CRP 4

\section{Results and Discussion}

To verify the effectiveness of the proposed detection technique, the FTBBR circuit is simulated by using PSIM simulation software. The waveforms of the output voltage and inductor current after the fault occurrence are the main reference to detect the location of the faulty switch. The fault is simulated by turning off the gate signal to the switch which needed to be simulated as OCF. Figure 3 shows an example of the output voltage and the inductor current waveforms during fault occurrence. The output voltage will drop and the inductor current will become zero at either positive or negative cycle. 


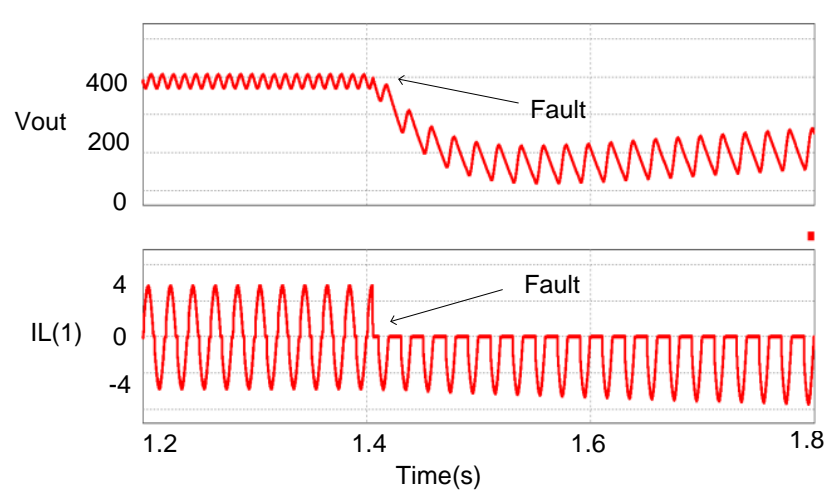

Fig. 3: The waveforms of the output voltage and inductor current before and after fault.

To further strengthen the analysis, the gate signals of the switches are also included to show the converter is running in which CRP before the fault is occurred. Figure 4(a-h) show the waveforms of output voltage, inductor current and gate voltage for all operation modes at positive cycle and negative cycle. Each cycle represents inductor current flow into a switch in particular mode of operation.
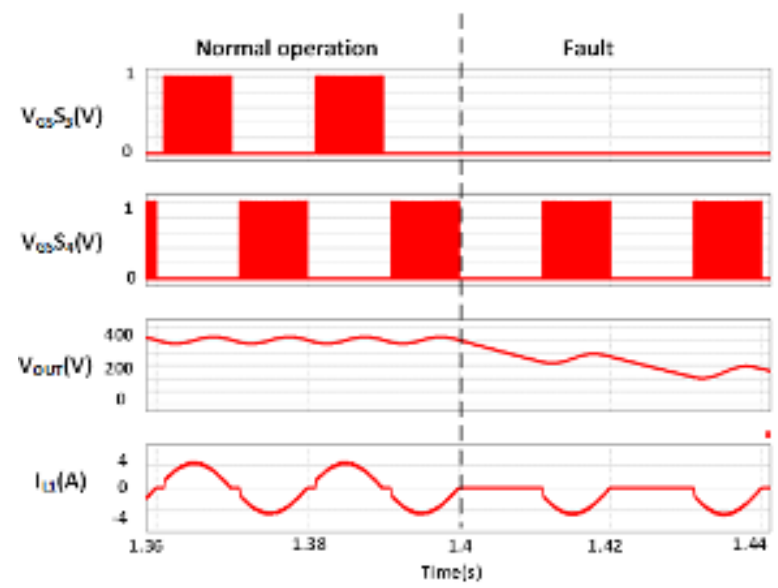

Fig. 4(a): CRP 1 when fault occurred at positive cycle

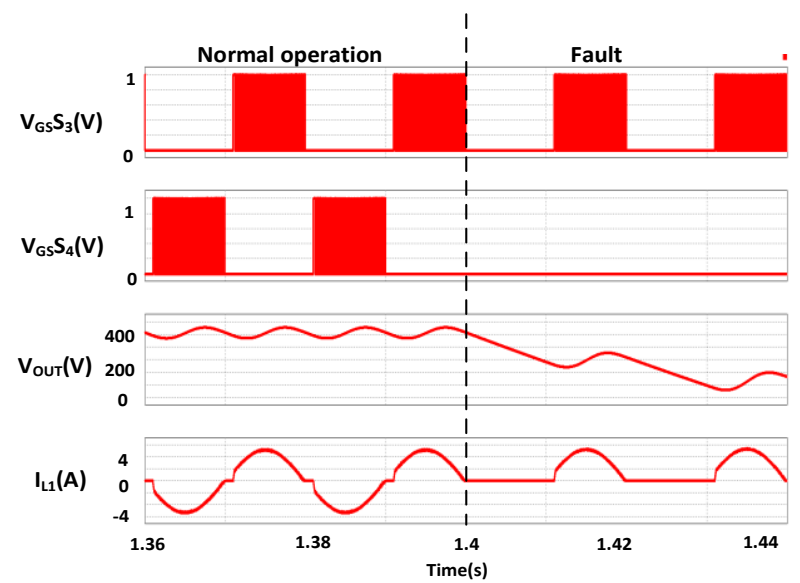

Fig. 4(b): CRP 1 when fault occurred at negative cycle

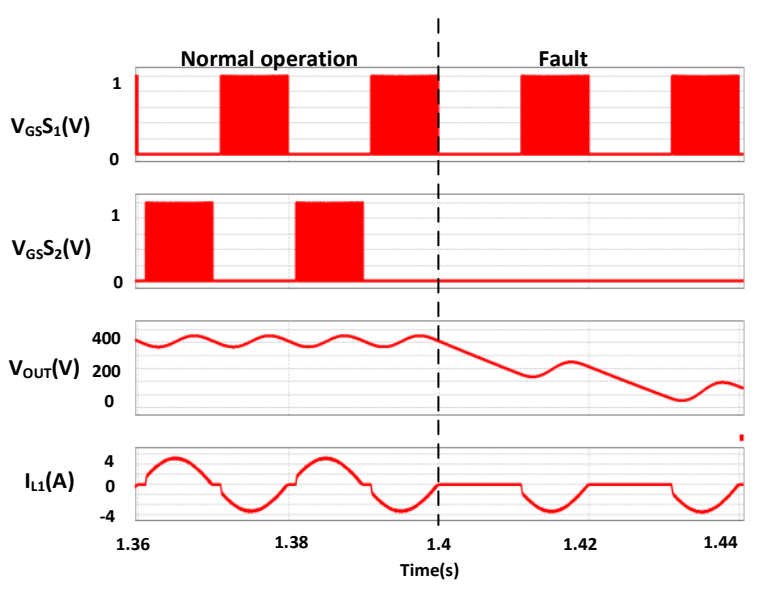

Fig. 4(c): CRP 2 when fault occurred at positive cycle
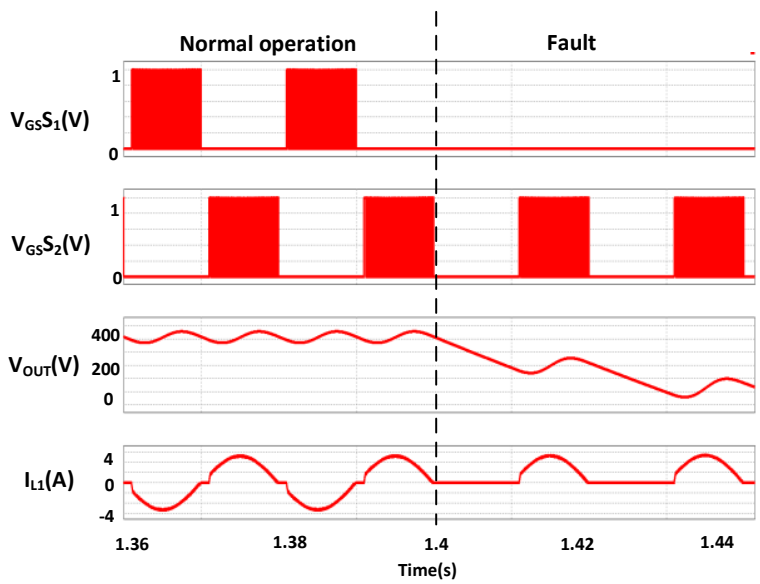

Fig. 4(d): CRP 2 when fault occurred at negative cycle

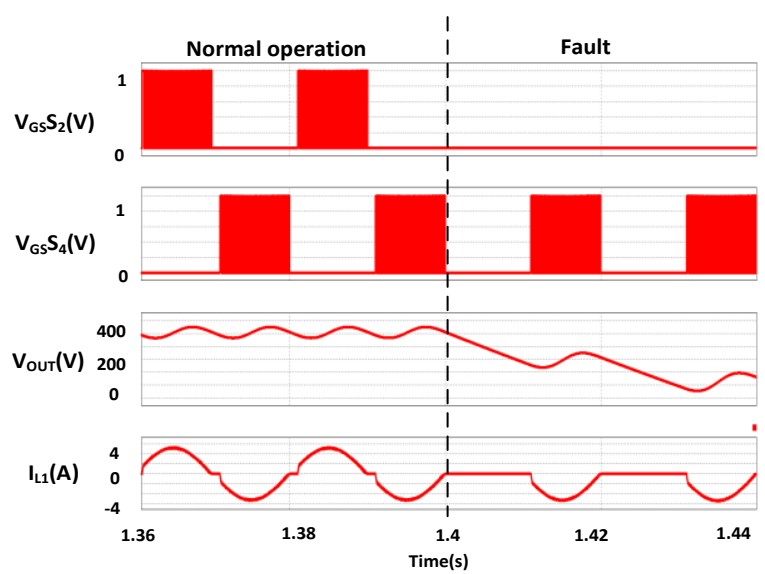

Fig. 4(e): CRP 3 when fault occurred at positive cycle 


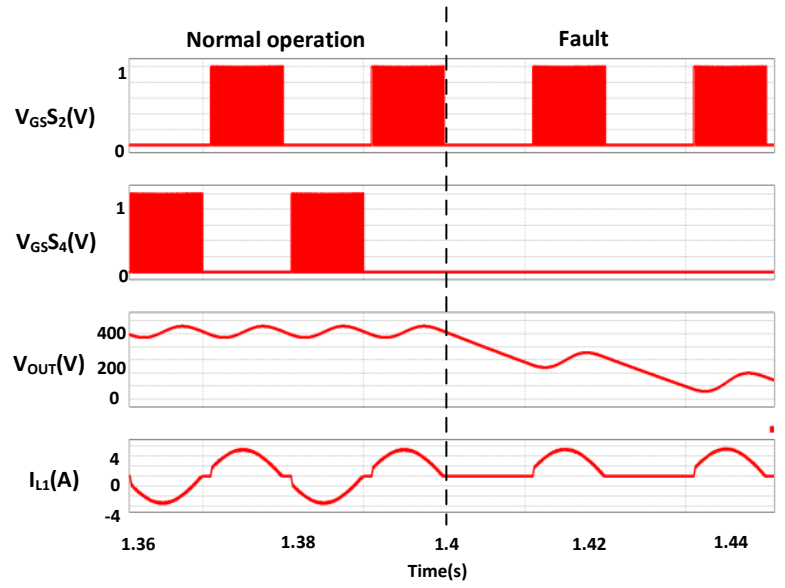

Fig. 4(f): CRP 3 when fault occurred at negative cycle

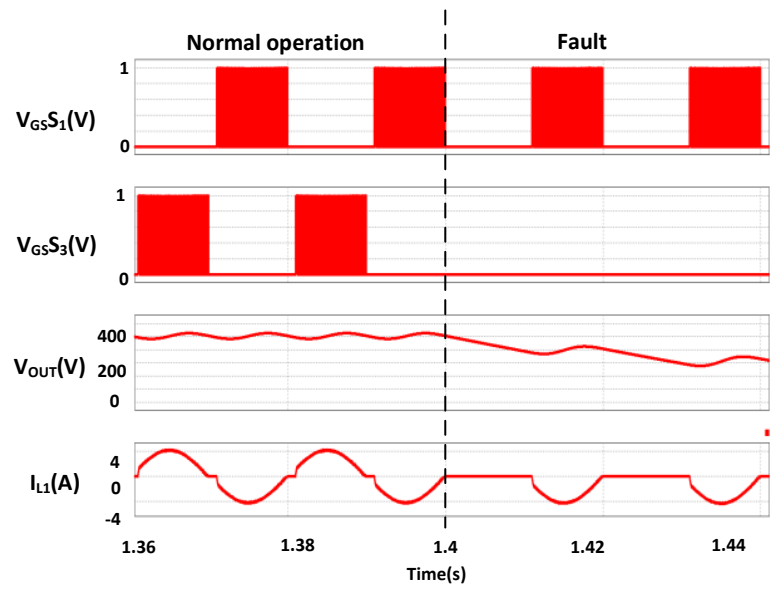

Fig. 4(g): CRP 4 when fault occurred at positive cycle
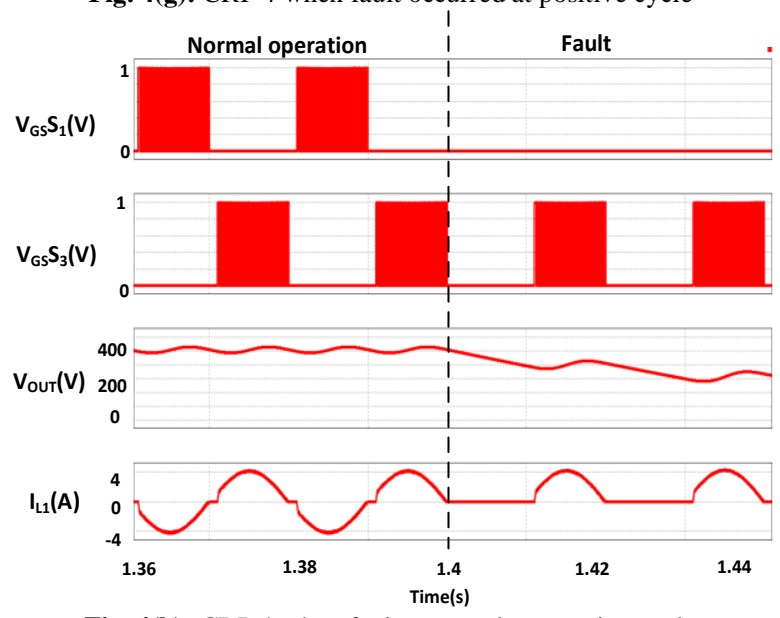

Fig. 4(h): CRP 4 when fault occurred at negative cycle

Table 2(a-h) show the values of the gate voltage and the inductor current at positive and negative cycle during charging and discharging process and the identification of fault occurrence for all CRPs. As an example, Table 2(a) shows the fault occurrence at positive cycle for CRP 1. During normal condition at charging state, the gate voltage for $S_{3}$ is $15 \mathrm{~V}$ and gate voltage for $S_{4}$ is $0 \mathrm{~V}$. This indicates that $S_{3}$ is turned-on and $S_{4}$ is turned-off at positive cycle. Meanwhile at discharging state, the gate voltage for $S_{3}$ and $\mathrm{S}_{4}$ are $0 \mathrm{~V}$, showing that both $\mathrm{S}_{3}$ and $\mathrm{S}_{4}$ are turned-off at positive cycle. For inductor current during normal condition at both charging and discharging state, the value of inductor current is positive value. However, during fault condition, the values of inductor current and gate voltages are zero. Compared to negative cycle, the values of inductor current and gate voltages at normal condition and fault condition are similar indicate that the fault occurrence only at positive cycle. The condition is similar for other CRPs.
Table 2(a): CRP 1 (Fault at Positive Cycle)

\begin{tabular}{|c|c|c|c|c|c|c|}
\hline & \multicolumn{5}{|c|}{ NORMAL } & \multicolumn{4}{c|}{ FAULT } \\
\hline \multicolumn{7}{|c|}{ POSITIV CYCLE } \\
\cline { 1 - 5 } MODE & IL1 & VGS3 & VGS4 & IL1 & VGS3 & VGS4 \\
\hline Charge & + & 1 & 0 & 0 & 0 & 0 \\
\hline Discharge & + & 0 & 0 & & & \\
\hline \multicolumn{7}{|c|}{ NEGATIVE CYCLE } \\
\hline MODE & IL1 & VGS3 & VGS4 & IL1 & VGS3 & VGS4 \\
\hline Charge & - & 0 & 1 & - & 0 & 1 \\
\hline Discharge & - & 0 & 0 & - & 0 & 0 \\
\hline
\end{tabular}

Table (2(b): CRP 1 (Fault at Negative Cycle)

\begin{tabular}{|c|c|c|c|c|c|c|}
\hline & \multicolumn{3}{|c|}{ NORMAL } & \multicolumn{4}{c|}{ FAULT } \\
\hline \multicolumn{7}{|c|}{ POSITIVE CYCLE } \\
\hline MODE & IL1 & VGS3 & VGS4 & IL1 & VGS3 & VGS4 \\
\hline Charge & + & 1 & 0 & + & 1 & 0 \\
\hline Discharge & + & 0 & 0 & + & 0 & 0 \\
\hline \multicolumn{7}{|c|}{ NEGATIVE CYCLE } \\
\hline MODE & IL1 & VGS3 & VGS4 & IL1 & VGS3 & VGS4 \\
\hline Charge & - & 0 & 1 & 0 & 0 & 0 \\
\hline Discharge & - & 0 & 0 & & & \\
\hline
\end{tabular}

Table 2(c): CRP 2 (Fault at Positive Cycle)

\begin{tabular}{|c|c|c|c|c|c|c|}
\hline & \multicolumn{5}{|c|}{ NORMAL } & \multicolumn{3}{c|}{ FAULT } \\
\hline \multicolumn{7}{|c|}{ POSITIVE CYCLE } \\
\hline MODE & IL1 & VGS1 & VGS2 & IL1 & VGS1 & VGS2 \\
\hline Charge & + & 0 & 1 & 0 & 0 & 0 \\
\hline Discharge & + & 0 & 0 & & & \\
\hline \multicolumn{7}{|c|}{ NEGATIVE CYCLE } \\
\hline MODE & IL1 & VGS1 & VGS2 & IL1 & VGS1 & VGS2 \\
\hline Charge & - & 1 & 0 & - & 1 & 0 \\
\hline Discharge & - & 0 & 0 & - & 0 & 0 \\
\hline
\end{tabular}

Table 2(d): CRP 2 (Fault at Negative Cycle)

\begin{tabular}{|c|c|c|c|c|c|c|}
\hline & \multicolumn{3}{|c|}{ NORMAL } & \multicolumn{4}{c|}{ FAULT } \\
\hline \multicolumn{7}{|c|}{ POSITIVE CYCLE } \\
\hline MODE & IL1 & VGS1 & VGS2 & IL1 & VGS1 & VGS2 \\
\hline Charge & + & 0 & 1 & + & 0 & 1 \\
\hline Discharge & + & 0 & 0 & + & 0 & 0 \\
\hline \multicolumn{7}{|c|}{ NEGATIVE CYCLE } \\
\hline MODE & IL1 & VGS1 & VGS2 & IL1 & VGS1 & VGS2 \\
\hline Charge & - & 1 & 0 & 0 & 0 & 0 \\
\cline { 1 - 4 } Discharge & - & 0 & 0 & & & \\
\hline
\end{tabular}


Table 2(e): CRP 3 (Fault at Positive Cycle)

\begin{tabular}{|c|c|c|c|c|c|c|c|}
\hline & \multicolumn{3}{|c|}{ NORMAL } & \multicolumn{4}{c|}{ FAULT } \\
\hline \multicolumn{7}{|c|}{ POSITIVE CYCLE } \\
\cline { 1 - 5 } MODE & IL1 & VGS2 & VGS4 & IL1 & VGS2 & VGS4 \\
\hline Charge & + & 1 & 0 & 0 & 0 & 0 \\
\hline Discharge & + & 0 & 0 & & & \\
\hline \multicolumn{7}{|c|}{ NEGATIVE CYCLE } \\
\hline MODE & IL1 & VGS2 & VGS4 & IL1 & VGS2 & VGS4 \\
\hline Charge & - & 0 & 1 & - & 0 & 1 \\
\hline Discharge & - & 0 & 0 & - & 0 & 0 \\
\hline
\end{tabular}

Table 2(f): CRP 2 (Fault at Negative Cycle)

\begin{tabular}{|c|c|c|c|c|c|c|c|}
\hline & \multicolumn{3}{|c|}{ NORMAL } & \multicolumn{4}{c|}{ FAULT } \\
\hline \multicolumn{7}{|c|}{ POSITIVE CYCLE } \\
\hline MODE & IL1 & VGS2 & VGS4 & IL1 & VGS2 & VGS4 \\
\hline Charge & + & 1 & 0 & + & 1 & 0 \\
\hline Discharge & + & 0 & 0 & + & 0 & 0 \\
\hline \multicolumn{7}{|c|}{ NEGATIVE CYCLE } \\
\hline MODE & IL1 & VGS2 & VGS4 & IL1 & VGS2 & VGS4 \\
\hline Charge & - & 0 & 1 & 0 & 0 & 0 \\
\hline Discharge & - & 0 & 0 & & & \\
\hline
\end{tabular}

Table 2(g): CRP 4 (Fault At Positive Cycle)

\begin{tabular}{|c|c|c|c|c|c|c|c|}
\hline & \multicolumn{5}{|c|}{ NORMAL } & \multicolumn{4}{c|}{ FAULT } \\
\hline \multicolumn{7}{|c|}{ POSITIVE CYCLE } \\
\hline MODE & IL1 & VGS1 & VGS3 & IL1 & VGS1 & VGS3 \\
\hline Charge & + & 0 & 1 & 0 & 0 & 0 \\
\hline Discharge & + & 0 & 0 & & & \\
\hline \multicolumn{7}{|c|}{ NEGATIVE CYCLE } \\
\hline MODE & IL1 & VGS1 & VGS3 & IL1 & VGS1 & VGS3 \\
\hline Charge & - & 1 & 0 & - & 1 & 0 \\
\hline Discharge & - & 0 & 0 & - & 0 & 0 \\
\hline
\end{tabular}

Table 2(h): CRP 4 (Fault At Negative Cycle)

\begin{tabular}{|c|c|c|c|c|c|c|}
\hline & \multicolumn{3}{|c|}{ NORMAL } & \multicolumn{4}{c|}{ FAULT } \\
\hline \multicolumn{7}{|c|}{ POSITIVE CYCLE } \\
\hline MODE & IL1 & VGS1 & VGS3 & IL1 & VGS1 & VGS3 \\
\hline Charge & + & 0 & 1 & + & 0 & 1 \\
\hline Discharge & + & 0 & 0 & + & 0 & 0 \\
\hline \multicolumn{7}{|c|}{ NEGATIVE CYCLE } \\
\hline MODE & IL1 & VGS1 & VGS3 & IL1 & VGS1 & VGS3 \\
\hline Charge & - & 1 & 0 & 0 & 0 & 0 \\
\hline Discharge & - & 0 & 0 & & & \\
\hline
\end{tabular}

\section{Conclusions}

A new open-circuit fault detection technique for FTBBR has been proposed in this paper. The detection technique can identify the exact location of the faulty switches under open-circuit fault occurrence by analyzing the output voltage, cycle of the input supply and inductor current. The detection method is simple enough to be practically implemented.

\section{Acknowledgement}

This work is fully support by Ministry of Higher Education Malaysia and The Institue of Research Management and Innovation (IRMI) Universiti Teknologi MARA, Grant No: 600 IRMI/PERDANA 5/3 BESTARI (067/2018). The financial assistance is gratefully acknowledged.

\section{References}

[1] S. Khwan-on, L. De Lillo, L. Empringham, P. Wheeler. FaultTolerant Matrix Converter Motor Drives with Fault Detection of Open Switch Faults. IEEE Transactions on Industrial Electronics. 2012; 59(1): 257-268.

[2] Gleissner M, Bakran M M. Design and Control of Fault-Tolerant Non-isolated Multiphase Multilevel DC-DC Converters for Automotive Power Systems. IEEE Transactions Industrial Applications. 2016; 52(2): 1785-1795.

[3] Gonzalez-Prieto, I Duran, M J, Che H S, Levi E, Bermúdez M, \& Barrero F. Fault-tolerant operation of six-phase energy conversion systems with parallel machine-side converters. IEEE Transactions Power Electronics. 2016; 31(4), 3068-3079

[4] M Salehifar, M Moreno-eguilaz, V Sala, R S Arashloo, L Romeral. Improved Open Switch Fault Detection Based on Normalized Current Analysis in Multiphase Fault Tolerant Converters. IEEE Transactions Industrial Electronics. 2013; 512-519.

[5] R Yahyaoui, A De Bernardinis, S I Fclab. Switch Short-Circuit Fault Detection Algorithm based on Drain-to-Source Voltage Monitoring for a Fault Tolerant DC / DC Converter. IEEE Transactions Industrial Electronics. 2016; 2212-2217.

[6] L Jacob, M Behrooz. Open-Circuit IGBT Fault Detection and Location Isolation for Cascaded Multilevel Converters. IEEE Transactions Industrial Electronics. 2017; 64(6): 4846-4856.

[7] M Abdelsalam, M I Marei, S Member, S B Tennakoon, A Modular. An Integrated Control Strategy with Fault Detection and Tolerant Control Capability Based on Capacitor Voltage Estimation for Modular Multilevel Converters. 2017; 53(3): 2840-2851.

[8] Houshang S, Hossein I E, Shahrokh F. Open Circuit Fault Detection and Localization in Modular Multilevel Converter. IEEE Transactions Industrial Power Electronics. 2015; 383-388.

[9] D Zhou, S Yang, S Member, Y Tang. A Voltage-Based OpenCircuit Fault Detection and Isolation Approach for Modular Multilevel Converters with Model Predictive Control. IEEE Transactions Industrial Power Electronics. 2018; 1-9.

[10] J L Soon, D D Lu. A Simple Open-Circuit Fault Detection Method for a Fault-Tolerant DC / DC Converter", IEEE PEDS. 2015; 98 103.

[11] H Givi, E Farjah, T Ghanbari. Switch and Diode Fault Diagnosis in Non-isolated DC-DC Converters Using Diode. IEEE Transactions Industrial Electronics. 2018; 65(2): 1606-1615

[12] K S Muhammad, R Baharom, M K Salleh, Dylan D. Open-Circuit Fault-Tolerant for Bridgeless Boost Rectifier. IEEE Transactions Industrial Electronics. 2016; 2201-2206 